\title{
PINCH RESISTOR ANALYTICAL MODELING WITH SIMPLE MODEL AND JFET MODEL FOR VLSI DESIGN
}

\author{
Pushpinder Singh', Balwant Raj', Balwinder Raj ${ }^{3}$ \\ ${ }^{1,3}$ University Centre for Instrumentation and Microelectronics (UCIM) \\ Panjab University Chandigarh, Chandigarh (India) \\ ${ }^{2}$ Sant Baba Bhag Singh Institute of Engineering and Technology, Jalandhar (India) \\ E-mail: 'balwinderraj@gmail.com
}

\begin{abstract}
Analytical modeling of pinch resistor has been carried out in this paper using the simple model and JFET model. The results obtained through the simple model are compared with the JFET model, which shows that the JFET model is more roburst for the VLSI design. The analysis and design of ICs depend heavily on the utilization of suitable models for IC components. A device technologist designs for circuits applications while process technologist develops process to fabricate these devices. For the same channel width and doping concentration for $\mathrm{N}_{\mathrm{d}}=5 \times 10^{16} / \mathrm{cm}^{3}$, the resistance of the pinch resistor 1.44 times greater than the $\mathrm{N}$-well device resistor, and for the doping concentration $\mathrm{N}_{\mathrm{d}}=5^{\star} 10^{17} / \mathrm{cm}^{3}$, the resistance of the pinch resistor 1.35 times greater than the $\mathrm{N}$-well device resistor.
\end{abstract}

Keywords: Wind Farm, Induction Generator, Point of Common Coupling (PCC), Voltage Source Converter (VSC), Flexible AC Transmission Systems (FACTS), Pulse Width Modulated (PWM) inverter.

\section{INTRODUCTION}

The fundamental goal in device modeling is to obtain fundamental relationship among the electrical variables of the device that is to be modeled. The electrical characteristics depend upon a set of parameters including both the geometrical variables and variables depend on the device physics. The sheet resistance can be increased of the $\mathrm{N}$-well resistor by diffusing a $\mathrm{P}^{+}$layer, which is made floating. The $\mathrm{P}^{+}$layer reduces the cross-section available to current flow. The $\mathrm{P}^{+}$layer also shields the resistor from above, thus eliminating the capacitive coupling between the resistor and any interconnection lines that might be passing above it. This resistor is called the pinch resistor because the conducting area is decreased for the current , and high values of sheet resistances is obtained, comparative to the $\mathrm{N}$-well. Typically the models are initially developed by analytically applying basic physical principles and then empirically modifying the resulting mathematical expressions to improve agreements between theoretical and experimental results. The $\mathrm{N}$-well resistor can be modeled in two ways:

1. Simple model of pinch resistor.

2. JFET model of pinch resistor.

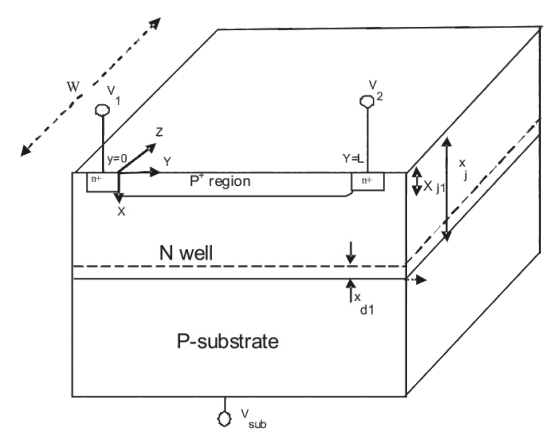

Fig. 1. Cross section along channel of Pinch resistor for simple model

\section{SIMPLE MODE OF PINCH RESISTOR}

In this model we assume the voltages at two terminals $\left(\mathrm{n}^{+}\right)$are same with respect to the substrate and doping concentration is same thought the $\mathrm{N}$-well. The figure shows the schematic of the $\mathrm{N}$-well device resistor used for modeling. There is a pn junction between the substrate and $\mathrm{N}$-well that is reversed biased in normol operation. The $\mathrm{P}^{+}$region made floating for the normal operation. The device resistance is mainly determined by the resistivity and the geometry is given as-

$$
\begin{aligned}
& 0 \text { d" y d" L; } \\
& 0 \text { d" z d"W; } \\
& 0 \text { d"x d"xj; }
\end{aligned}
$$

Where $x_{i}$ is the depth of the $\mathrm{N}$-well to substrate metallurgical junction and $L$ is the length of the channel and $W$ is the width of the channel. A depletion region exists 
at the bottom side and ends of sidewall the $\mathrm{N}$-well region. The depletion region thickness and thus resistance of the device is modeled by junction bias.

By taking an assumption that we are applying a same voltage on both $\mathrm{n}^{+}$terminals, the resulting thickness of the depletion region will be constant through out the junction. Let the substrate terminal is at ground potential. Since we are taking only $n$ side depletion region in account.

The depletion layer between the $p$-substrate and $n$ well region is given as:

$$
X_{d 1}=\left(\frac{2 \varepsilon_{S i} N_{a 1}}{q N_{d}\left(N_{a}+N_{d}\right)}\right)^{1 / 2}\left(V+V_{b i 1}\right)^{/ 2}
$$

The depletion layer between the $p^{+}$cap and n-well region is given as:

$$
X_{d 2}=\left(\frac{2 \varepsilon_{S i} N_{a 2}}{q N_{d}\left(N_{a}+N_{d}\right)}\right)^{1 / 2}\left(V_{b i 2}\right)^{1 / 2}
$$

Built in potential between the $p$-substrate and n-well region

$V_{b i 1}=\frac{K T}{q} \ln \left(\frac{N_{a 1} N_{d}}{n_{i}^{2}}\right)$

Built in potential between the $p^{+}$cap and $n$-well region

$$
V_{b i 2}=\frac{K T}{q} \ln \left(\frac{N_{a 2} N_{d}}{n_{i}^{2}}\right)
$$

The resistivity of the $\mathrm{N}$-well is given by

$$
p=\frac{1}{q N_{d} \mu}
$$

The dependence of mobility on doping concentration is given as

$$
\mu=\mu_{\min }+\frac{\mu_{\max }-\mu_{\min }}{1+\left(\frac{N}{N_{\text {ref }}}\right)^{\alpha}}
$$

Now sheet resistance is given as

$$
R_{s h}=\frac{p}{X_{n}}
$$

Where

$$
X_{n}=X_{j}-X_{j 1}-X_{d 1}-X_{d 2}
$$

And the total resistance will be

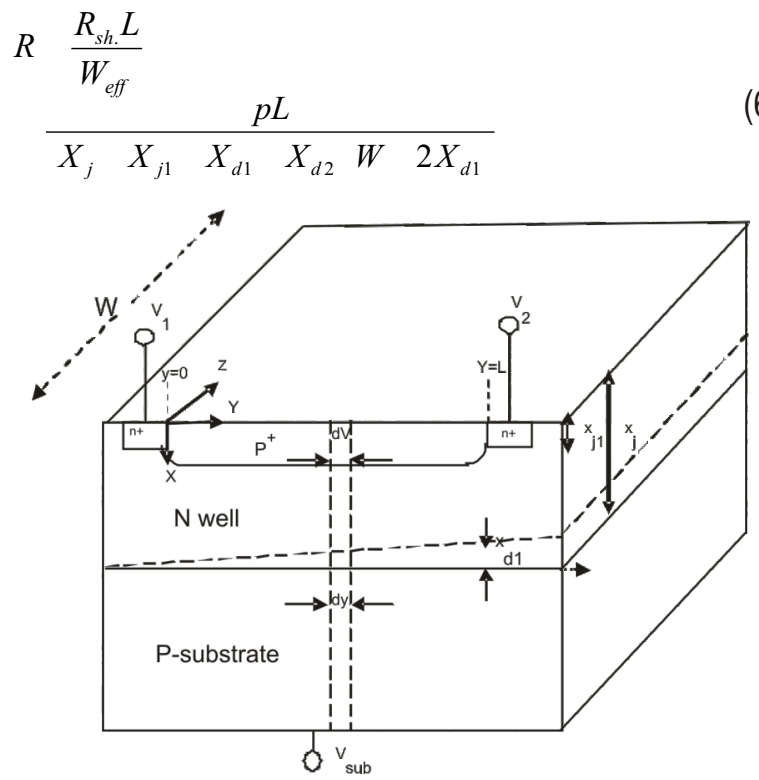

Fig. 2. Cross section along channel of Pinch Resistor for Advance (JFET) model.

\section{JFET MODEL OF PINCH RESISTOR}

The schematic diagram used for modeling of pinch resistor as a JFET model is shown in figure (2). In practical circuit, there is a voltage difference across the resistor terminals $V_{1}$ and $V_{2}$. Therefore the depletion width will linearly increase from terminal $V_{1}$ to terminal $V_{2}$ and resistor can be modeled as a JFET. The device geometry is same as in simple model.

The depletion region thickness and thus resistance of the device is modeled by the junction bias. Let at a position $y$ along the length of the N-well resistor, an infinitesimally small slice with thickness dy has a voltage drop dV. The width and the depth of the conducting (undepleted) portion of the resistor at this point in the channel are functions of the local resistor body bias with respect to the substrate.

Assuming an abrupt junction, the channel depth at point $y$ is given by

$$
X_{n}(y)=X_{j}-X_{j 1}-X_{d 1}-X_{d 2}
$$

Where depletion width in $\mathrm{N}$-well region is given as

The depletion layer between the $p$-substrate and $n$ well region

$$
\begin{aligned}
X_{d 1} & =\left(\frac{2 \varepsilon_{S i} N_{a 1}}{q N_{d}\left(N_{a}+N_{d}\right)}\right)^{1 / 2}\left(V_{y}+V_{b 1}\right)^{1 / 2} \\
& =A_{1}\left(V_{y}+V_{b 1}\right)^{/ 2}
\end{aligned}
$$


Where

$$
A_{1}=\frac{2 \varepsilon_{s} N_{a 1}}{q\left(N_{a 1}+N_{d}\right) N_{d}}
$$

The depletion layer between the $\mathrm{p}^{+}$cap and n-well

$$
\begin{gathered}
X_{d 2}=\left(\frac{2 \varepsilon_{S i} N_{a 2}}{q N_{d}\left(N_{a}+N_{d}\right)}\right)^{1 / 2}\left(V_{b i 2}\right)^{1 / 2} \\
=A_{2}\left(V_{b 2}\right)^{1 / 2} \\
A_{2}=\frac{\left(2 \varepsilon_{s i} N_{a 2}\right)}{q\left(N_{a 2}+N_{d}\right)}
\end{gathered}
$$

Where $\quad V_{Y}$ is resistorbody ( $\mathrm{N}$-well) to substrate bias aty.

$\mathrm{N}_{\mathrm{a} 1}$ is doping concentration of substrate

$\mathrm{N}_{\mathrm{a} 2}$ is doping concentration of $\mathrm{p}^{+}$region.

$\mathrm{N}_{\mathrm{d}}$ is doping concentration of $\mathrm{N}$-well.

Built in potential between the $p$-substrate and $n$ well region

$$
V_{b i 1}=\frac{K T}{q} \ln \left(\frac{N_{a 1} N_{d}}{n_{i}^{2}}\right)
$$

Built in potential between the $p^{+}$cap and $n$-well region

$$
V_{b i 2}=\frac{K T}{q} \ln \left(\frac{N_{a 2} N_{d}}{n_{i}{ }^{2}}\right)
$$

The equation of the current density through the slice is given as

$$
J=q n v_{d}
$$

Where $v_{d}$ is the drift velocity of the carrier.

$$
J=q n \mu E
$$$$
J=q n \mu \frac{d V}{d y}
$$

Thus, the current through the infinitesimally small slice with dy length has a potential $\mathrm{dV}$ is given by multiplying cross sectional area with current density.

$$
\begin{aligned}
& \left.I_{d}=q N_{d} \mu\left(X_{n}\right)\left(W_{e f f}\right) \frac{d V}{d y}\right) \\
& I_{d}=q N_{d} \mu\left(X_{j}-X_{j 1}-X_{d 1}-X_{d 2}\right)\left(W_{e f f}-2 X_{d 1}\right)\left(\frac{d V}{d y}\right) \\
& !={ }_{q} N_{a}\left[\left(X_{j}-X_{j 1}-A_{2} \cdot\left(V_{b 2}\right)^{1 / 2}-A_{1}\left(V_{y}+V_{b 1}\right)^{2}\right)\left(W-2 \cdot A_{1} \cdot\left(V_{y}+V_{b 1}\right)^{2}\right)\right]
\end{aligned}
$$

Let $C_{1}=q N_{d} \mu$

$$
C_{2}=X_{j}-X_{j 1}-A_{2} \cdot\left(V_{b 2}\right)^{1 / 2}
$$

$$
\mathrm{I}_{d}=C_{1}\left[\left(C_{2}-A_{2} \cdot V_{b 1}\right)^{1 / 2}\left(W-2 \cdot A_{1} \cdot\left(V_{y}+V_{b 1}\right)^{\prime 2}\right)\right]_{d v}^{d Y}
$$$$
I_{d}=\left[C_{1} C_{2} W-C_{1} \cdot A_{1}\left(V_{y}+V_{b}\right)^{2} \cdot W-C_{1} \cdot C_{2} \cdot 2 A_{1}\left(V_{y}+V_{b l}\right)^{2}+C_{1} \cdot 2 \cdot A_{1}^{2}\left(V_{y}+V_{b b}\right)\right]_{d y}^{d V}
$$

$I_{d} d y=C_{1}\left[C_{2} W-\left(W+2 \cdot C_{2}\right)\left(V_{y}+V_{b 1}\right)^{2} \cdot A_{1}+2 \cdot A_{1}^{2} \cdot\left(V y+V_{b b}\right)\right] d V$

Integrating above equation with limit $0 \mathrm{~d}$ " $\mathrm{y} d$ " $L$ and 0 d" V d" Vd, we will get total current flowing through the $\mathrm{N}$ well and given as

$\mathrm{I}_{\mathrm{d}}=C_{1}\left[C_{2} W \cdot V_{d}-\left(W+2 \cdot C_{2}\right)\left(V_{y}+V_{b 1}\right)^{\prime 2} \cdot A_{1} \cdot \frac{2}{3}+A_{1}^{2} \cdot\left(V y+V_{b 1}\right)\right]$

Taking Limits

$$
\begin{gathered}
\mathrm{I}_{d}=\frac{C_{1}}{L}\left[C_{2} W \cdot V_{d}-\frac{2}{3} \cdot\left(W+2 \cdot C_{2}\right) A_{1}\left[V_{d}+V_{b 1}\right)^{3 / 2}-V_{b 1}^{3 / 2}\right]+A_{1}^{2}\left[\left(V_{y}+V_{b 1}\right)-V_{b 1}{ }^{2}\right] \\
I_{d}=\frac{C_{1}}{L}\left[C_{2} W V_{d}-\frac{2}{3}\left(W+2 C_{2}\right) A_{1}\left[\left(V_{d}+V_{b 1}\right)^{3 / 2}-V_{b 1}^{3 / 2}\right]+A_{1}^{2}\left[V_{d}^{2}+V_{b 1}^{2}+2 V_{d} V_{b 1}-V_{b 1}^{2}\right]\right] \\
I_{d}=\frac{C_{1}}{L}\left[C_{2} W V_{d}-\frac{2}{3}\left(W+2 C_{2}\right) A_{1}\left[\left(V_{d}+V_{b 1}\right)^{3 / 2}-V_{b 1}^{3 / 2}\right]+A_{1}^{2}\left[V_{d}^{2}+2 V_{d} V_{b 1}\right]\right]
\end{gathered}
$$

Therefore, the resistance of the pinch resistor will be

$$
R=\frac{V}{I_{d}}
$$

\section{PINCH RESISTOR}

Resistances at different voltages with different $\mathrm{w}$

(a) At $\mathrm{N}_{\mathrm{d}}=5^{*} 10^{16} \mathrm{~cm}^{-3} \& \mathrm{X}_{\mathrm{J} 1}=1 \mathrm{um}$

Table 1. For simple model

\begin{tabular}{|l|c|c|}
\hline Voltage (V) & $\begin{array}{l}\mathrm{W}=2.5 \mu \mathrm{m} \\
\mathrm{R}\left(10^{4} ?\right)\end{array}$ & $\begin{array}{l}\mathrm{W}=5 \mu \mathrm{m} \\
\mathrm{R}\left(10^{4} ?\right)\end{array}$ \\
\hline 1 & 2.3951 & 1.1195 \\
\hline 2 & 2.5174 & 1.1544 \\
\hline 3 & 2.6268 & 1.1848 \\
\hline 4 & 2.7288 & 1.2123 \\
\hline 5 & 2.8261 & 1.2378 \\
\hline
\end{tabular}

Table 2. For JFET model

\begin{tabular}{|l|l|l|}
\hline Voltage (V) & $\begin{array}{l}\mathrm{W}=2.5 \mu \mathrm{m} \\
\mathrm{R}\left(10^{4} ?\right)\end{array}$ & $\begin{array}{l}\mathrm{W}=5 \mu \mathrm{m} \\
\mathrm{R}\left(10^{4} ?\right)\end{array}$ \\
\hline 1 & 2.2916 & 1.0912 \\
\hline 2 & 2.3756 & 1.1147 \\
\hline 3 & 2.4407 & 1.1331 \\
\hline 4 & 2.4982 & 1.1493 \\
\hline 5 & 2.5514 & 1.1641 \\
\hline
\end{tabular}


(b) At $\mathrm{N}_{\mathrm{d}}=5^{*} 10^{17} \mathrm{~cm}^{-3} \& \mathrm{X}_{\mathrm{J} 1}=1 \mathrm{um}$

Table 3. For simple model

\begin{tabular}{|l|l|l|}
\hline Voltage (V) & $\begin{array}{l}\mathrm{W}=2.5 \mu \mathrm{m} \\
\mathrm{R}\left(10^{4} ?\right)\end{array}$ & $\begin{array}{l}\mathrm{W}=5 \mu \mathrm{m} \\
\mathrm{R}\left(10^{4} ?\right)\end{array}$ \\
\hline 1 & 0.45822 & 0.22717 \\
\hline 2 & 0.46092 & 0.22803 \\
\hline 3 & 0.46320 & 0.22876 \\
\hline 4 & 0.46521 & 0.22940 \\
\hline 5 & 0.46703 & 0.22997 \\
\hline
\end{tabular}

Table 4. For JFET model

\begin{tabular}{|l|l|l|}
\hline Voltage (V) & $\begin{array}{l}\mathrm{W}=2.5 \mu \mathrm{m} \\
\mathrm{R}\left(10^{4} ?\right)\end{array}$ & $\begin{array}{l}\mathrm{W}=5 \mu \mathrm{m} \\
\mathrm{R}\left(10^{4} ?\right)\end{array}$ \\
\hline 1 & 0.45643 & 0.22661 \\
\hline 2 & 0.45803 & 0.22711 \\
\hline 3 & 0.45938 & 0.22754 \\
\hline 4 & 0.46059 & 0.22793 \\
\hline 5 & 0.46170 & 0.22828 \\
\hline
\end{tabular}

(c) At $\mathrm{N}_{\mathrm{d}}=5^{\star} 10^{16} \mathrm{~cm}^{-3} \& \mathrm{X}_{\mathrm{j} 1}=3 \mathrm{um}$

Table 5. For simple model

\begin{tabular}{|l|l|l|}
\hline Voltage $(\mathrm{V})$ & $\begin{array}{l}\mathrm{W}=2.5 \mu \mathrm{m} \\
\mathrm{R}\left(10^{5} ?\right)\end{array}$ & $\begin{array}{l}\mathrm{W}=5 \mu \mathrm{m} \\
\mathrm{R}\left(10^{4} ?\right)\end{array}$ \\
\hline 1 & 0.9345 & 4.3720 \\
\hline 2 & 1.0262 & 4.7059 \\
\hline 3 & 1.1123 & 5.0168 \\
\hline 4 & 1.1970 & 5.3177 \\
\hline 5 & 1.2820 & 5.6152 \\
\hline
\end{tabular}

Table 6. For JFET model

\begin{tabular}{|l|l|l|}
\hline Voltage (V) & $\begin{array}{l}\mathrm{W}=2.5 \mu \mathrm{m} \\
\mathrm{R}\left(10^{5} ?\right)\end{array}$ & $\begin{array}{l}\mathrm{W}=5 \mu \mathrm{m} \\
\mathrm{R}\left(10^{4} ?\right)\end{array}$ \\
\hline 1 & 0.8409 & 4.0814 \\
\hline 2 & 0.9114 & 4.3118 \\
\hline 3 & 0.9629 & 4.4908 \\
\hline 4 & 1.0082 & 4.6500 \\
\hline 5 & 1.0504 & 4.7996 \\
\hline
\end{tabular}

(d) At $N_{d}=5^{*} 10^{17} \mathrm{~cm}^{-3} \& X_{j 1}=1 \mathrm{um}$

Table 7. For simple model

\begin{tabular}{|l|l|l|}
\hline Voltage (V) & $\begin{array}{l}\mathrm{W}=2.5 \mu \mathrm{m} \\
\mathrm{R}\left(10^{3} ?\right)\end{array}$ & $\begin{array}{l}\mathrm{W}=5 \mu \mathrm{m} \\
\mathrm{R}\left(10^{3} ?\right)\end{array}$ \\
\hline 1 & 4.5822 & 2.2717 \\
\hline 2 & 4.6092 & 2.2803 \\
\hline 3 & 4.6320 & 2.2876 \\
\hline 4 & 4.6521 & 2.2940 \\
\hline 5 & 4.6703 & 2.2997 \\
\hline
\end{tabular}

Table 8. For JFET model

\begin{tabular}{|l|l|l|}
\hline Voltage (V) & $\begin{array}{l}\mathrm{W}=2.5 \mu \mathrm{m} \\
\mathrm{R}\left(10^{3} ?\right)\end{array}$ & $\begin{array}{l}\mathrm{W}=5 \mu \mathrm{m} \\
\mathrm{R}\left(10^{3} ?\right)\end{array}$ \\
\hline 1 & 4.5643 & 2.2661 \\
\hline 2 & 4.5803 & 2.2711 \\
\hline 3 & 4.5938 & 2.2754 \\
\hline 4 & 4.6059 & 2.2793 \\
\hline 5 & 4.6170 & 2.2828 \\
\hline
\end{tabular}

(e) At $\mathrm{N}_{\mathrm{d}}=5^{\star} 10^{17} \mathrm{~cm}^{-3} \& \mathrm{X}_{\mathrm{j} 1}=3 \mathrm{um}$

Table 9. For simple model

\begin{tabular}{|l|l|l|}
\hline Voltage (V) & $\begin{array}{l}\mathrm{W}=2.5 \mu \mathrm{m} \\
\mathrm{R}\left(10^{4} ?\right)\end{array}$ & $\begin{array}{l}\mathrm{W}=5 \mu \mathrm{m} \\
\mathrm{R}\left(10^{3} ?\right)\end{array}$ \\
\hline 1 & 1.4462 & 7.1700 \\
\hline 2 & 1.4603 & 7.2244 \\
\hline 3 & 1.4721 & 7.2703 \\
\hline 4 & 1.4826 & 7.3109 \\
\hline 5 & 1.4922 & 7.3477 \\
\hline
\end{tabular}

Table 10. For JFET model

\begin{tabular}{|l|l|l|}
\hline Voltage (V) & $\begin{array}{l}\mathrm{W}=2.5 \mu \mathrm{m} \\
\mathrm{R}\left(10^{4} ?\right)\end{array}$ & $\begin{array}{l}\mathrm{W}=5 \mu \mathrm{m} \\
\mathrm{R}\left(10^{3} ?\right)\end{array}$ \\
\hline 1 & 1.4365 & 7.1338 \\
\hline 2 & 1.4451 & 7.1661 \\
\hline 3 & 1.4522 & 7.1933 \\
\hline 4 & 1.4585 & 7.2177 \\
\hline 5 & 1.4642 & 7.2399 \\
\hline
\end{tabular}

Fig. Of Pinch resistor for simple model for:-

$\mathrm{N}_{\mathrm{d}=} 5^{*} 10^{16} / \mathrm{cm}^{3}$, w=2.5um, $\mathrm{xjl}=1 \mathrm{um}$.

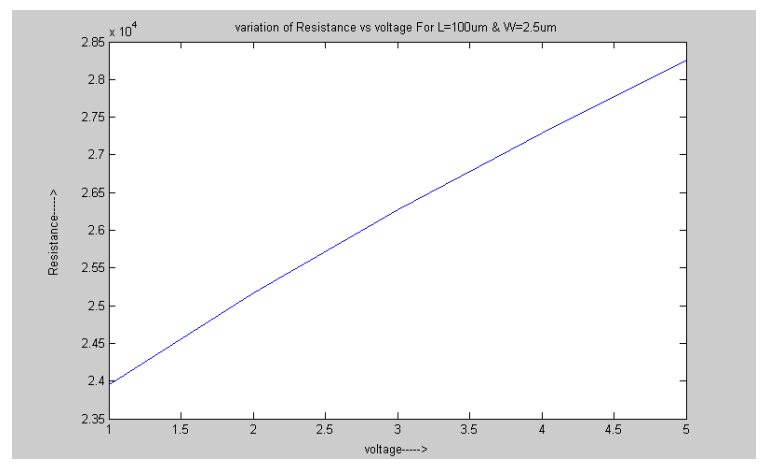

Fig. of the pinch resistor for simple model:-

$\mathrm{N}_{\mathrm{d}}=5 * 10^{16} / \mathrm{cm}^{3}, \mathrm{~W}=2.5 \mathrm{um}, \mathrm{X}_{\mathrm{j}}=3 \mathrm{um}$

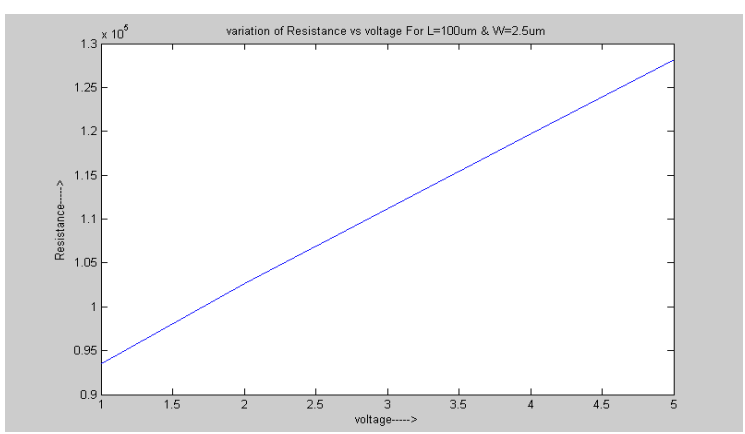


Fig. of the for pinch resistor for simple model :$\mathrm{N}_{\mathrm{d}}=5 * 10^{16} / \mathrm{cm}^{3}, \mathrm{~W}=5 \mathrm{um}, \mathrm{X}_{\mathrm{j} 1}=3 \mathrm{um}$

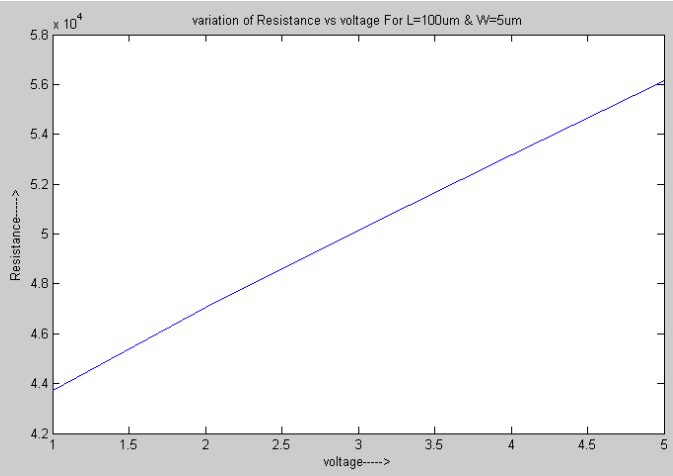

Fig.of Pinch resistor for simple model:-

$\mathrm{N}_{\mathrm{d}}=5 * 10^{17} / \mathrm{cm}^{3}, \mathrm{~W}=2.5 \mathrm{um}, \mathrm{X}_{\mathrm{j} 1}=1 \mathrm{um}$

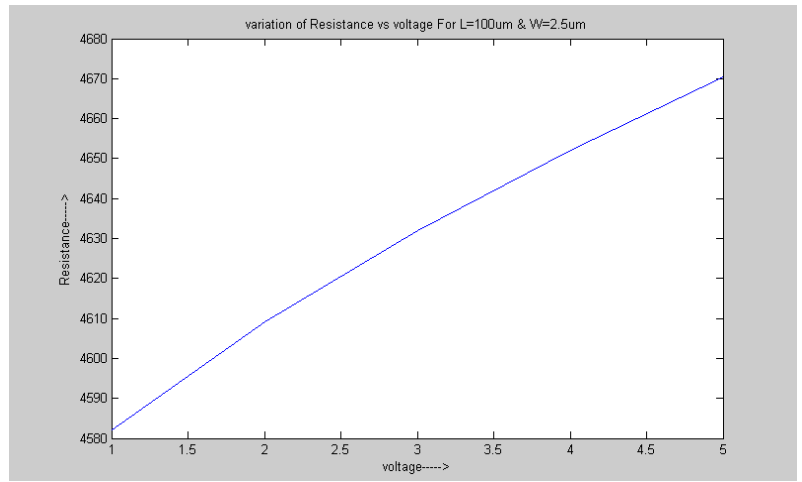

Fig .of pinch resistor for simple model:

$\mathrm{N}_{\mathrm{d}}=5 * 10^{17} / \mathrm{cm}^{3}, \mathrm{~W}=2.5 \mathrm{um}, \mathrm{X}_{\mathrm{j} 1}=3 \mathrm{um}$

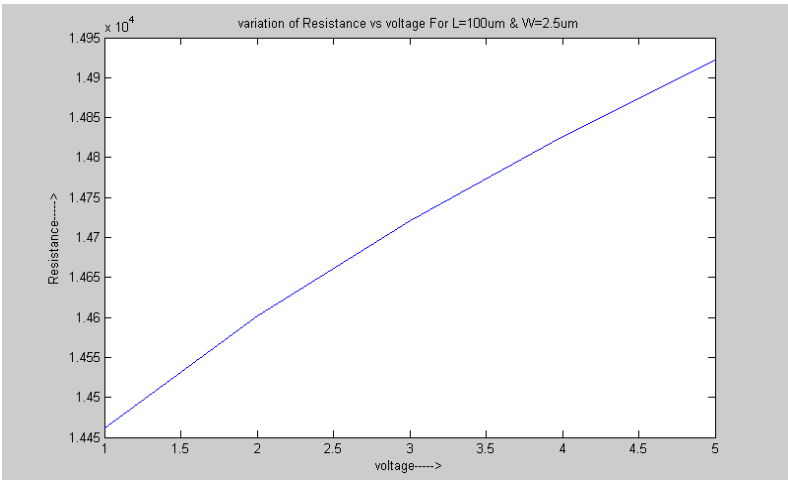

Fig. of pinch resistor for simple model:-

$\mathrm{N}_{\mathrm{d}}=5 * 10^{17} / \mathrm{cm}^{3}, \mathrm{~W}=5 \mathrm{um}, \mathrm{X}_{\mathrm{ji}}=3 \mathrm{um}$

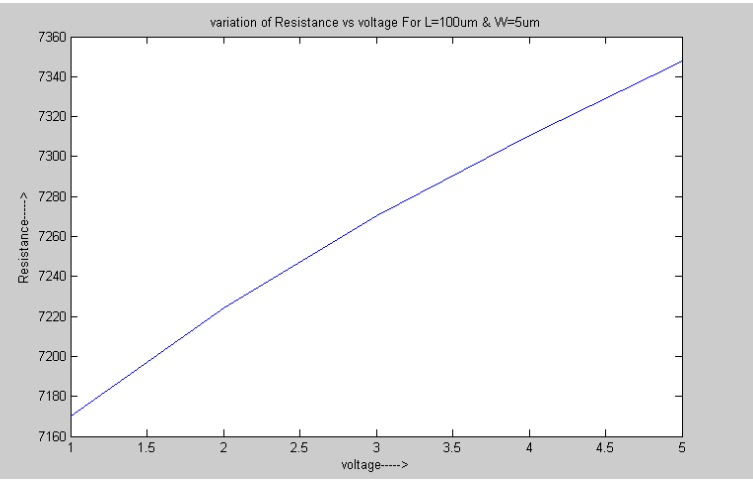

Fig of pinch resistor for JFET model for:

$\mathrm{N}_{\mathrm{d}}=5 * 10^{16} / \mathrm{cm}^{3}, \mathrm{~W}=2.5 \mathrm{um}, \mathrm{X}_{\mathrm{j} 1}=1 \mathrm{um}$

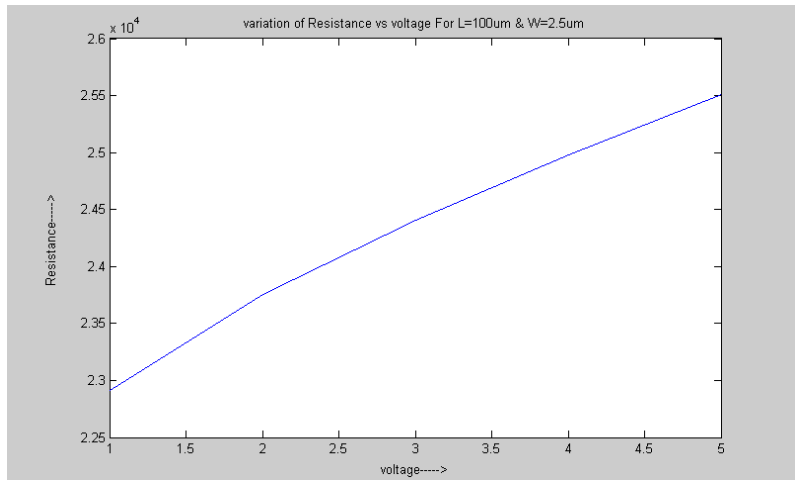

Fig .of Pinch resistor for JFET model for:-

$\mathrm{N}_{\mathrm{d}}=5 * 10^{16} / \mathrm{cm}^{3}, \mathrm{~W}=5 \mathrm{um}, \mathrm{X}_{\mathrm{j1}}=1 \mathrm{um}$

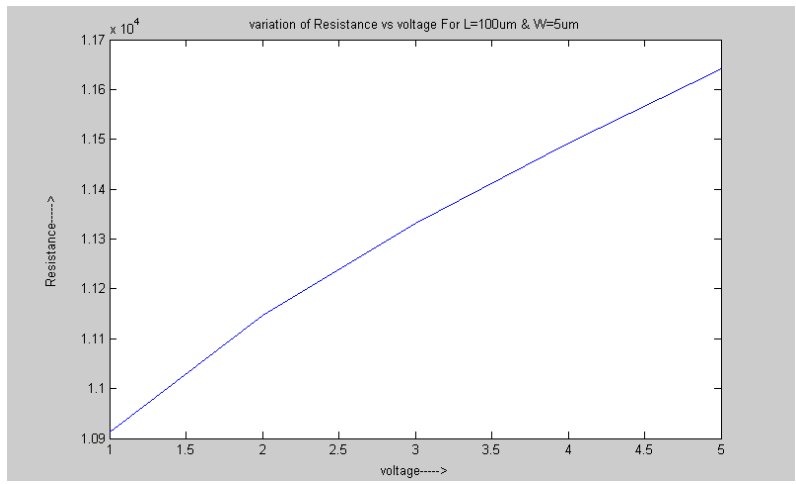

Fig. of the pinch resistor for the JFET model for :$\mathrm{N}_{\mathrm{d}}=5^{*} 10^{16}, \mathrm{~W}=2.5 \mathrm{um}, \mathrm{X}_{\mathrm{j} 1}=3 \mathrm{um}$

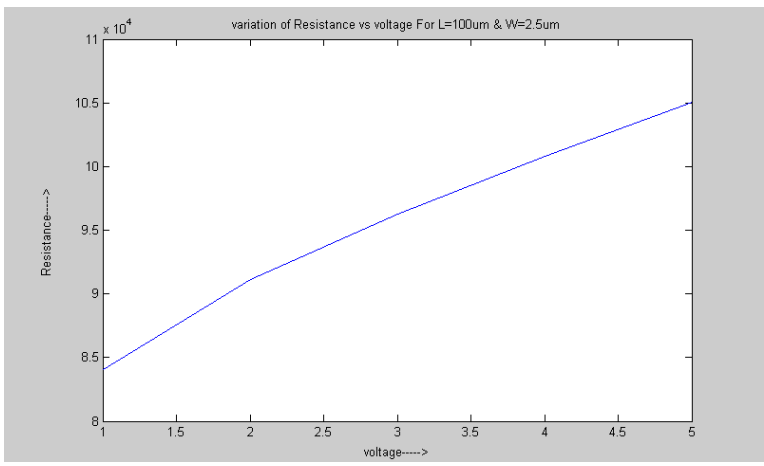

Fig.of Pinch resistor for the JFET model for-

$\mathrm{N}_{\mathrm{d}}=5 * 10^{16} / \mathrm{cm}^{3}, \mathrm{~W}=5 \mathrm{um}, \mathrm{X}_{\mathrm{j} 1}=3 \mathrm{um}$

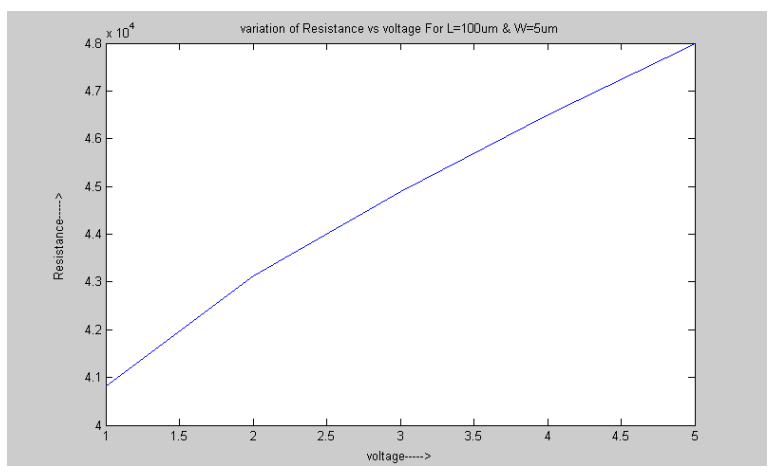


Fig. of pinch resistor for JFET model for:$\mathrm{N}_{\mathrm{d}}=5 * 10^{17} / \mathrm{cm}^{3}, \mathrm{~W}=2.5 \mathrm{um}, \mathrm{X}_{\mathrm{j} 1}=3$

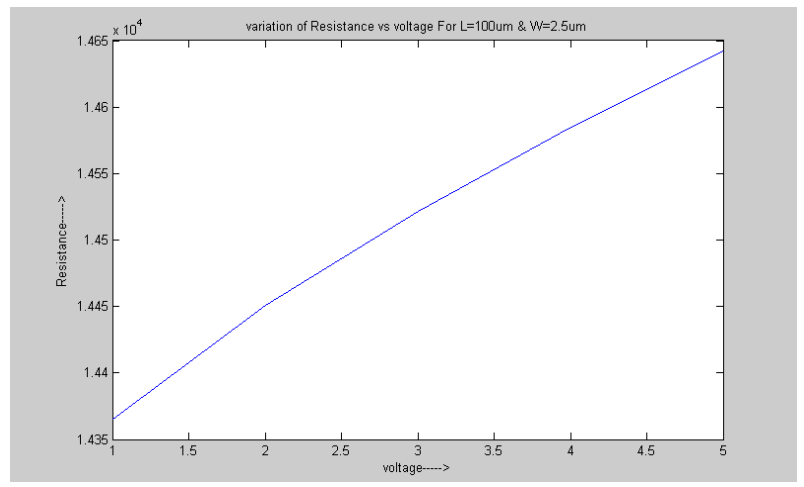

Fig.of Pinch resistor for JFET model for:-

$\mathrm{N}_{\mathrm{d}}=5 * 10^{17} / \mathrm{cm}^{3}, \mathrm{~W}=5 \mathrm{um}, \mathrm{X}_{\mathrm{j} 1}=3$

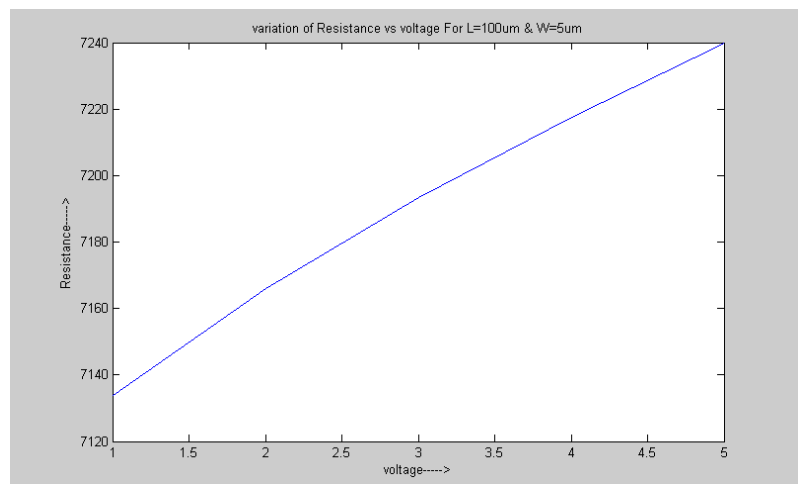

\section{CONCLUSION}

In this paper analytical modeling of pinch resistor has been carried out using the simple model and JFET model. The results obtained through the simple model are compared with the JFET model, which shows that the JFET model is more roburst for the VLSI design. For the same channel width and doping concentration for $\mathrm{N}_{\mathrm{d}}=$ $5^{*} 10^{16} / \mathrm{cm}^{3}$, the resistance of the pinch resistor 1.44 times greater than the $\mathrm{N}$-welll device resistor, and for the doping concentration $\mathrm{N}_{\mathrm{d}}=5^{\star} 10^{17} / \mathrm{cm}^{3}$, the resistance of the pinch resistor 1.35 times greater than the $\mathrm{N}$-well device resistor.
For the same channel width and doping concentration for $N_{d}=5^{*} 10^{16} / \mathrm{cm}^{3}$, the resistance of the pinch resistor(for depth of the layer $\left.\mathrm{P}^{+} \mathrm{X}_{\mathrm{j} 1}=3 \mathrm{um}\right) 6$ times greater than the $\mathrm{N}$ welll device resistor, and for the doping concentration $\mathrm{N}_{\mathrm{d}}=5^{*} 10^{17} / \mathrm{cm}^{3}$, the resistance of the pinch resistor (for depth of the layer $\mathrm{P}^{+} \mathrm{X}_{\mathrm{j} 1}=3 \mathrm{um}$ ) 4.2 times greater than the $\mathrm{N}$ well device resistor.

\section{REFERENCES}

[1] Booth R.H. Mc Andrew c.c, 1997, " A 3-Terminal Model for diffused and lon implanted Resistors", IEEE Trans. Electron Devices, Vol. 44. No.5, Pp 809-814.

[2] "Modeling of Voltage Dependent Diffused Resistors", 1997, Akira Ito, IEEE Trans. Electron devices, Vol. 44, No-12.

[3] "A Four-Terminal Compact Model for High Voltage Diffused Resistors with Field Plates", 1998, James Victory, Coli C. McAndrew, Senior Member, IEEE, Jeff Hall, and Mike Zunino, IEEE Journal of solid state circuits, vol. 33, No.

[4] Muller R.S., Kamins T.I. "Device electronics for Integrated Circuits", second Edition, John Wily \& Sons, New York.

[5] Effic V. Axelrad, N. Cobb, M. O'Brien, V. Boksha, T. Do, T. Donnelly, Y. Granik, E.Sahouria, A. Balasinskiient, "Full-Chip Yield Analysis Methodology for OPCCorrected VLSI Designs," Cypress Semiconductor, San Jose, CA.

[6] J.-O. Plouchart, N. Zamdmer, J. Kim, M. Sherony Y. Tan, A. Ray, M. Talbi, L. F. Wagner, K. Wu,2003, "Application of an SOI $0.12 \mu \mathrm{m}$ CMOS technology to SoCs with low-power and high-frequency circuits", IBM J. RES. \& DEV. Vol. 47 No. 5/6

[7] Ying Huang, "Current-Mode CMOS Image Sensor", 2002, A thesis presented to the electrical engineering department, University of Waterloo. 